\title{
LETRAS GUINEANAS, PASOS NECESARIOS
}

POR

\author{
JuAN TOMÁs Ávila LaURel
}

La atención suscitada por Guinea por su disponibilidad del petróleo y por la explotación del mismo por parte de las empresas multinacionales estadounidenses corre pareja con el avance que se ha producido en su literatura. La necesidad de focalizar la atención en el aspecto económico de Guinea descansa en la realidad de que los ingresos económicos provenientes de la venta del crudo y del gas generarían una riqueza que coadyuvaría a elevar sus índices estadísticos, entre los que se encuentran los que reflejan el verdadero nivel de vida de los habitantes de esta República de Guinea Ecuatorial. Esto es, qué comen, cómo lo hacen, y que condiciones reúnen los habitáculos en que realizan esta actividad vital por excelencia. Y es que alcanza el cielo alto los lamentos de la gente cuando se descubre que en muchos sitios de Guinea hay muchos que comen en los pesebres, como las bestias carentes de entidad racional.

Los avances económicos que se espera que impriman un cambio al estatus vital de los guineoecuatorianos son equiparables a los avances producidos o esperados en su literatura, toda vez que hay muchos que suponen que una bonanza económica implica inmediatamente un desarrollo en su literatura. Pero toda vez que la industria editorial requiere de una disponibilidad económica para que sus proyectos se lleven a cabo, la asociación entre la riqueza dineraria de Guinea y una literatura emergente y sostenible es inmediata.

Al margen de estas consideraciones, y sin postergar al remoto olvido las esperanzas de un desarrollo nacional, expresado en todas sus vertientes humanas y sociales, creemos que cinco son los pasos que hay que dar para que las letras guineanas encuentren el lugar que le corresponde en el contexto en que se les exige que brillen, a tenor de las consideraciones históricas que envuelven al país, a saber: África hispana, Europa, América hispana. Vista la demarcación histórica, toca ahora señalar los pasos ineludibles para situar a la literatura guineana en el lugar que le corresponde:

El robustecimiento de la educación nacional, sin el cual la cantera de los futuros escritores se vería cercenada, toda vez que una educación integral que incluye 
todas las fases asegura que las nuevas generaciones crezcan no ya solamente como potenciales escritores, sino como el germen de una masa lectora, ineludible en una literatura con intenciones de llevar la impronta de lo patrio. El reconocimiento y la promoción incondicional de todos los actores actuales de la literatura nacional, pues la disgregación a la que están sometidos, sumado al olvido deliberado de algunos por la clase política dominante, resta cohesión, requisito por la cual la etiqueta de "nacional" sería discutible. Sin la necesaria cohesión o agrupación, la periodización no tendría sentido, pues las obras de los autores y los mismos se estudiarían de manera aislada, por lo que no se podría establecer ninguna relación entre ellos. Entonces los futuros analistas o investigadores de esa literatura no podrían establecer relaciones o conexiones entre ellos, hecho ineludible y necesario para establecer vínculos a la hora de catalogar o identificar paralelismos o influencias de unas épocas o autores sobre otros y otras.

El compromiso con la labor editorial, la edición y difusión de las obras literarias dentro del territorio nacional contribuiría a la apropiación de los ciudadanos guineanos de la historia ficcionalizada de sus vidas, por lo que la interacción entre lectores y escritores sería el germen de una dependencia económica y literaria que sostendría la labor de los autores, al asegurarse un mínimo de ingreso económico por su labor. La necesidad de las condiciones anteriores se complementaría con la existencia de un cuerpo solvente de críticos nativos o foráneos, pero sin la exclusión de alguna de las componentes, habida cuenta de que existen ciertos aspectos autóctonos que solamente los investigadores nativos sabrían diseccionar para una cabal comprensión de los textos sujetos a sus investigaciones. No podemos dejar de señalar que la "nacionalización" de la literatura guineana contribuiría también a la puesta en marcha de la una industria editorial nacional, todavía inexistente o en fase rudimentaria. El robustecimiento de la industria editorial guineana crearía oportunidades laborales y de innovación tecnológica, necesarias para la modernización del país.

Hasta ahora el acceso de los guineanos residentes en Bata y en Malabo a las obras literarias de los autores guineanos es sin mediación del intercambio económico, propiciado por la distribución gratuita de las mismas por parte de los centros culturales españoles de las mencionadas ciudades. No se sostendrían ninguno de los supuestos anteriores si este acceso gratuito se sigue produciendo, ya que la necesaria valoración del autor no se haría, desbaratando por ello todos los supuestos aleccionadores esperados, impidiendo, además, que desde Guinea se lleve a cabo el establecimiento de una mínima infraestructura editorial, postergando los beneficios tecnológicos y laborales que eso conlleva.

El compromiso nacional aludido arriba comprende igualmente la celebración de eventos en torno a la literatura, donde se expongan refuten o pongan en común los puntos de vista sobre las obras escritas, lo que imprimirá un dinamismo y activará las potencialidades dormidas de los autores. Amenudo se olvida que la actividad literaria se

Revista Iberoamericana, Vol. LXXX, Núms. 248-249, Julio-Diciembre 2014, 1123-1125 
realiza en soledad, necesaria para la expresión de las mencionadas facultades dormidas; este hecho imprime su impronta en el carácter de los autores, cuya sensibilidad a veces es acusada, en relación a sus congéneres. En el compromiso nacional exigido se requiere el reconocimiento de esta realidad, pues lo óptimo es que cada autor reciba las atenciones de acuerdo a su particular sensibilidad, ya que, al fin y al cabo, su sensibilidad particular es la generadora de las obras a las que debe el renombre o el reconocimiento.

La inclusión de la literatura patria en el currículum educativo nacional hará que la misma y sus efectos beneficiosos, desarticulados en sus aspectos sociales, económicos, ejerzan de efecto aleccionador entre la población en general, que junto con la mejora de la educación y los otros puntos aludidos arriba, la robustecerían, al ver las nuevas generaciones el efecto de estos beneficios sobre los autores. Es noticia pública en los países subdesarrollados la constatación del estado de abandono y de pobreza en la que viven los artistas, inclusive los escritores, al margen de la calidad de sus obras, e incluso aunque estas fueran geniales. Como la historia es recurrente, con los escritores del tercer mundo, y en concreto los de Guinea, podemos revivir la historia de un embajador que visita a uno de ellos y, constatado su deplorable estado de vida, exclamó lo que ya quedó registrado para el pasmo de la Historia: ¿A tal hombre no lo tiene España muy rico y sustentado del erario ...?

Revista Iberoamericana, Vol. LXXX, Núms. 248-249, Julio-Diciembre 2014, 1123-1125 
